\title{
Propuesta didáctica de EFE en el campo de la logística y aduana
}

\author{
María Nayra Rodríguez Rodríguez ${ }^{1}$ \\ Universidad de Las Palmas de Gran Canaria \\ Sara González Gil \\ Universidad de Las Palmas de Gran Canaria
}

\begin{abstract}
International trading relationships between the five continents grow everyday. Some territories, such as the Canary Islands, require external contact to develop their economy. In a region like this, to be fluent in any language is not only essential for any profession, but it turns to be especially necessary in trading, in general, and in logistics and Customs, in particular. These Islands receive many international professionals that work in positions related to Customs, directly or indirectly. Therefore, we believe it is indispensable to develop a didactic program focusing on familiarizing these individuals with the Spanish logistics and Customs jargon. We will also get students acquainted with various text types that they will use as workers of logistics and Customs in Spain.
\end{abstract}

Keywords: Spanish for specific purposes (SSP), didactics, Spanish for trading, Spanish for logistics and Customs

\section{Resumen}

Las relaciones comerciales entre los cinco continentes crecen cada día. En un territorio que precisa del contacto exterior para desarrollar su economía, como las Islas Canarias, el dominio de diversas lenguas no es solo primordial en cualquier profesión, sino que se torna especialmente necesario en el comercio, en general, y en el campo de la logística y aduana, en particular. Debido a que las Islas reciben a muchos trabajadores del exterior para

Corresponding author - Universidad de Las Palmas de Gran Canaria, Departamento de Filología Española, Clásica y Árabe, Gran Canaria (Spain). Email: nayra.rodriguez@ulpgc.es 
incorporarse a puestos de trabajo relacionados directa o indirectamente con Aduanas, creemos que es imprescindible contar con una propuesta didáctica que se centre, precisamente, en que estos individuos dominen el tecnolecto correspondiente a esta profesión. Nos centraremos en aportar diversos contenidos lingüísticos que puedan trabajarse a través de distintos contextos situacionales, así como en familiarizar al alumnado con la diversa tipología textual a la que tendrá que enfrentarse como trabajador del campo de la logística y aduana en España.

Palabras clave: español con fines específicos (EFE), aplicación didáctica, español de los negocios, español de la logística y aduana

\section{Introducción}

El objetivo de este trabajo consiste en elaborar una propuesta didáctica destinada a profesionales del área de los negocios, con el fin de que estos adquieran destrezas comunicativas y culturales en español. No obstante, además de la propuesta didáctica, hemos realizado un recorrido sobre las principales aportaciones de la Lingüística Aplicada en este campo en concreto. Para llevar a cabo nuestro propósito, nos centraremos en la adquisición de los contenidos a través de contextos situacionales de inmersión lingüística en una compañía de logística y aduana, como por ejemplo, Copox Logística y Aduana S.L., localizada en las Islas Canarias, por ser esta región un modelo de economía que precisa del contacto comercial exterior. Enmarcamos el presente estudio en la disciplina de la Enseñanza del Español con Fines Específicos (en adelante, EFE). Situamos la propuesta didáctica en el ámbito profesional, que "abarca todo lo relativo a las actividades y las relaciones de una persona en el ejercicio de su profesión" Marco común europeo de referencia para las lenguas (MCER) (2002, p. 15).

La lengua española está adquiriendo un papel cada vez más importante y, en un mundo globalizado como el de nuestra sociedad actual, el tener conocimientos sobre el español de los negocios cobra especial interés. Hemos escogido el campo de la logística y la aduana porque, en un territorio limitado como lo son las Islas Canarias, toda la mercancía que abastece al sector terciario proviene del exterior y los trámites aduaneros son necesarios para cualquier importación legal. Por el contrario, la exportación en Canarias es escasa, pues las Islas cuentan con muy pocas industrias. Solo destacan la exportación de petróleo y la de productos alimenticios provenientes de la agricultura, como el plátano o el tomate, sobre todo a otros lugares de España $y$, en menor medida, a Gran Bretaña. 
La relevancia de los puertos de Canarias reside en el gran valor mercantil que tienen para la zona y, además, en el sector pesquero, ya que es un territorio muy próximo al banco pesquero canario-sahariano. Asimismo, es de obligada mención aludir al gran número de pasajeros de cruceros que visita Canarias cada año (casi dos millones en el año 2014) y que contribuye al desarrollo del sector turístico en las Islas. Por otro lado, el Puerto de la Luz y de Las Palmas (el principal en la isla de Gran Canaria y en la provincia de Las Palmas) es de amplio interés para la economía de esta región ultraperiférica de la Unión Europea. Es el cuarto puerto más importante de España, además de ser una escala tradicional de avituallamiento de buques en su paso desde Europa hacia América. Sus muelles son esenciales para el desarrollo socioeconómico del continente africano, pues, entre otras razones, el Puerto de la Luz y de Las Palmas es base logística del Programa Mundial de Alimentos (PMA) de la ONU, que aporta un millón de toneladas de alimentos al año a África.

Por otro lado, en los últimos años, muchos empresarios han decidido instalarse en las Islas Canarias, en concreto, en las dos capitales de las Islas (Las Palmas de Gran Canaria y Santa Cruz de Tenerife). Esto es debido a las ventajas fiscales que ofrecen las Islas, ya que se sitúan dentro de la jurisdicción de la Unión Europea, pero su sistema de impuestos difiere del resto de España e incluso del resto de Europa. Asimismo, una gran cantidad de estos trabajadores deciden trasladarse a Canarias para desarrollar su negocio o para comerciar con diferentes mercados africanos como Marruecos, Senegal, Cabo Verde o Mauritania. No es impedimento que no dominen la lengua española para desarrollar su trabajo, pero es una buena herramienta para relacionarse con otros empresarios del sector y para familiarizarse con los trámites requeridos en Aduanas.

Para elaborar esta propuesta didáctica, partimos de la hipótesis de la necesidad perentoria que tienen los profesionales de este sector (tanto en Canarias, como en todo el mundo hispanohablante) de conocer un lenguaje específico para realizar transacciones comerciales de diversa índole y de acercarse a un sector que lidia con diversas especificidades de las instituciones fiscales de cada país.

\section{Propiedades del tecnolecto}

El lenguaje de los negocios se caracteriza -como todo lenguaje específico- por hacer uso de un léxico propio que debe ser reconocido por sus aprendientes, así como de ciertas formas gramaticales determinadas. En el caso concreto de este trabajo, el alumnado aprendiente de EFE en el contexto de la logística y la 
aduana tiene ya una formación y una experiencia profesional relevante en este campo, por lo que será capaz de reconocer diversas características del tecnolecto y relacionarlas con su lengua y cultura de origen.

Asumimos que el lenguaje de la logística y la aduana, como el lenguaje de los negocios, posee terminología específica, donde es destacable la presencia de siglas. No obstante, la característica principal de esta lengua de especialidad reside en la diversa tipología textual que emplea, ya que es un campo de especialidad que tiene que lidiar a diario con diversos procesos administrativos exigidos por el Gobierno de cada Comunidad Autónoma española o por Hacienda del Estado (en el caso de una agencia de logística y aduana de España). Del mismo modo, el aspecto sociocultural es destacable, sobre todo por el hecho de que el estudiante de esta rama de EFE deberá asimilar una determinada información concerniente a las relaciones aduaneras en cada país, que pueden diferir de las de su país de origen.

Por último, cabe señalar que, en la actualidad, una empresa de logística y aduana en España realiza los trámites correspondientes con las instituciones de forma telemática, por lo que el lenguaje de esta especialidad se caracteriza también por hacer uso de textos informáticos, en forma de formularios.

\section{Fundamentación teórica}

En primer lugar, el Diccionario Virtual del Instituto Cervantes ${ }^{2}$ define la Enseñanza de la lengua para fines específicos de la siguiente forma:

La enseñanza de la lengua para fines específicos se centra en los procesos de enseñanza-aprendizaje que facilitan el dominio de la comunicación especializada, esto es, la lengua que utilizan los profesionales que trabajan en un determinado contexto laboral o los expertos que desarrollan su actividad en una disciplina académica concreta. [...]

La denominación EFE (Español con Fines Específicos) se extiende a comienzos de la década de los 90 y desde entonces la didáctica de este tipo de comunicación ha pasado a constituir una de las ramas más relevantes de la enseñanza del español como lengua extranjera. La evolución que ha tenido lugar en las instituciones educativas españolas públicas y privadas en relación con los procesos de enseñanza-aprendizaje implicados en este campo ha llevado a establecer una división de estas enseñanzas en dos grandes grup

Consultado el 14 de abril de 2015. 
a. el Español con fines profesionales (EFP)

b. el Español con fines académicos (EFA)

Dentro del campo de EFE, el lenguaje de los negocios entra en la subdisciplina de Español con fines profesionales (EFP).

Como hemos especificado anteriormente, nuestra propuesta didáctica estará destinada al español de los negocios, en concreto al campo de la logística y la aduana. Como bien señala Gómez de Enterría (2007, p. 149), es imprescindible tener en cuenta, al menos al comienzo, la naturaleza de las lenguas de especialidad. La descripción de la lengua objeto del proceso de aprendizaje supone un factor indispensable para la formación del docente. Es por ello, por lo que consideramos necesario aportar la descripción que nos ofrece el Diccionario de la Real Academia ${ }^{3}$ sobre lo que entendemos por logística y aduana en el contexto de los negocios:

Logística: Conjunto de medios y métodos necesarios para llevar a cabo la organización de una empresa, o de un servicio, especialmente de distribución.

Aduana: Oficina pública, establecida generalmente en las costas y fronteras, para registrar, en el tráfico internacional, los géneros y mercaderías que se importan o exportan, y cobrar los derechos que adeudan.

En cuanto a la ciencia que determina los lenguajes específicos, Calvi (2004, p.111) apunta que es tarea de la sociolingüística, pues su objeto de estudio es la variación lingüística debida a factores sociales. Por lo tanto, las lenguas de especialidad se relacionan con los registros, puesto que son variedades de la lengua determinadas por su uso y por un criterio sociológico que corresponde a los conocimientos compartidos por un grupo social (Rodríguez Díez, 1981). En un segundo plano queda el aporte de la glotodidáctica, ya que se ocupa de aportar propuestas metodológicas centradas en las necesidades del alumno.

De acuerdo con Calvi et al. (2009), las lenguas para fines específicos, también denominadas, entre otras formas, como lenguas de especialidad:

son variedades funcionales de la lengua que se han desarrollado como instrumentos de comunicación en un determinado ámbito científico o profesional. Se basan en estructuras fonéticas, gramaticales y léxicas de una lengua natural y se caracterizan por la formación de una terminología

Consultado el 14 de abril de 2015. 
propia, así como por la preferencia por ciertas formas gramaticales y discursivas (p.15).

Las lenguas de especialidad se caracterizan, en general, por tener un carácter unívoco y objetivo; por poseer un léxico exclusivo que evita la polisemia y las connotaciones; por hacer uso de una amplia terminología y de un uso específico de la gramática general y por no tener variaciones significativas en el plano fonético-fonológico (Aguirre Beltrán, 2004b y Moreno Fernández, 1999). En este sentido, Calvi et al. (2009) recogen que Cabré (1993) destaca que las unidades terminológicas no se analizan de forma abstracta, sino que los investigadores optan por estudiarlas dentro del funcionamiento discursivo real, teniendo en cuenta factores contextuales.

Por lo tanto, el proceso de enseñanza-aprendizaje de una lengua de especialidad está determinado, según Aguirre Beltrán (2004b, p. 1123), por los siguientes factores:

c. Al ser una enseñanza especializada, se tiene una actitud determinada hacia la lengua y sugiere unos temas, conceptos, nociones, tipología de textos y actividades específicas.

d. Se fundamenta en el análisis de necesidades, que incluye las necesidades de aprendizaje y determina las destrezas y estrategias que se deben trabajar.

e. El periodo de impartición es limitado y los alumnos suelen ser adultos profesionales o académicos.

f. El docente necesita adquirir una formación especializada en el EFE.

Con referencia a la propia formación del profesor de EFE del campo de los negocios, Fajardo Domínguez (2000) menciona:

Para que un profesor de español de los negocios entienda un texto de manera apropiada, necesitará conocer los conceptos y presuposiciones. La ignorancia de estos significados dentro del texto como un todo, significa no comprenderlo. Por lo que no tendrá más remedio que centrar su atención en la gramática y en el vocabulario (p. 198).

\subsection{Análisis de necesidades}

Este concepto, asevera Aguirre Beltrán (2004a) hace referencia al "conjunto de procedimientos que permite obtener información sobre lo que un alumno necesita aprender, o bien sobre sus expectativas o preferencias con respecto a un programa previsto" (p. 648). Es un recurso ineludible para el profesor en 
cualquier planteamiento a priori del proceso de enseñanza-aprendizaje de lenguas de especialidad. Aguirre Beltrán (2004b) destaca que:

Para fijar los objetivos hay que comenzar llevando a cabo un análisis de necesidades lo más pormenorizado posible con objeto de identificar los requisitos de comunicación que plantean las distintas situaciones-meta y compararlos con el grado actual de conocimientos de los aprendices de la lengua. También es posible que haya que tener en cuenta los requisitos de la institución o empresa que organiza el curso (p. 1121).

La autora (2004a, p. 648) recoge que Dudley-Evans y St. John (1998, p. 125) consideran que el concepto actual de análisis de necesidades abarca la determinación de los siguientes aspectos:

g. Información profesional sobre los alumnos: análisis de la situación meta o necesidades objetivas.

h. Información personal sobre los estudiantes: experiencia de aprendizaje previa, información cultural, razones para acudir al curso y expectativas.

i. Información sobre el nivel de conocimientos lingüísticos del alumno.

\subsection{Metodología}

En el ámbito profesional en el que se desarrolla el proceso de enseñanzaaprendizaje de EFE, el docente debe sopesar la concepción funcionalpragmática que caracteriza a este lenguaje. La metodología de los lenguajes con fines profesionales requiere que se consideren los procesos de comunicación verbal y no verbal, lingüísticos y no lingüísticos, así como la inclusión de las múltiples formas de la tecnología de la comunicación. Tal metodología tiene que asegurar que nuestros alumnos de EFE adquieran la competencia necesaria para desenvolverse en diversos contextos a partir de un análisis de necesidades, tal y como hemos mencionado (Aguirre Beltrán, 2004b, p. 1115-1116).

Respecto a la metodología, Calvi (2004, p. 113) afirma que el profesorado debe emplear un enfoque didáctico que desarrolle en el alumno la capacidad de observación. Gómez de Enterría (2007, p. 149) subraya, en este sentido, la relevancia de la función comunicativa, pues es el principal objetivo que el alumno debe alcanzar en el aprendizaje de una lengua de especialidad. Respecto a la interacción comunicativa, Neila González (2010) apunta que debe ser el verdadero motor del aprendizaje y señala las condiciones que enunciaron Hernández y Zanón (1990, p. 13-18) para que la interacción en clase sea comunicativa: 
j. Que los alumnos dispongan de los contenidos necesarios para incorporarse a la situación.

k. Que posean una razón para implicarse en una actividad de descodificación.

I. Que exista una situación en la que otro interlocutor proporcione información.

m. Que el estudiante disponga de una intención comunicativa como marco de referencia sobre el que evaluar el resultado de la interacción con objeto de decidir la coordinación o finalización de la operación.

Dado el papel que posee la función comunicativa en el proceso de enseñanzaaprendizaje de un lenguaje de especialidad, Gómez de Enterría (2007, p. 161) plantea que el docente debe iniciar el estudio de la lengua con fines específicos elaborando un corpus textual (tanto de los discursos orales como escritos) del ámbito de la especialidad. En cuanto a la utilización de textos en la clase de EFE, la autora (2007) añade que:
Los documentos auténticos son el medio con el que el profesor puede acercar hasta el aula los textos de la lengua de especialidad propuesta, tanto orales como escritos. Estos textos informan y muestran la variedad de documentos de cada actividad profesional. Además, favorecen la funcionalidad, es decir, una inmersión en las situaciones comunicativas especializadas en las que se debe situar la comunicación (p. 160).

Además, también puntualiza que en la actualidad su utilidad en el proceso de enseñanza-aprendizaje es indiscutible, aunque, en todo caso, el profesor debe valorar dichos textos como vehículos de comunicación especializada y como instrumentos imprescindibles para la enseñanza del EFE. Destaca, por otro lado, las particularidades lingüísticas que se abordan dentro de los textos.

Sobre la tipología textual de la comunicación profesional, Aguirre Beltrán (2004b) señala que "es muy amplia y, para su clasificación, se aplica el concepto de género, [...] aspecto clave que hay que considerar al establecer la programación de un curso de lengua para la comunicación profesional" (p. 1119). Sobre el concepto del género, Calvi (2004) expone que:

Cada lengua con fines específicos contempla una serie de géneros peculiares, que utilizan tanto el canal escrito como el oral con diferentes niveles de formalización. Algunos se atienen a una disciplina determinada y presentan una alta concentración de tecnicismos; otros emplean un léxico mixto, con una fuerte base de lengua común (artículo divulgativo, folleto, etc.) (p.109). 
Calvi et al. (2009) incluyen en su estudio la definición de Swales (1990) y Bhatia (1993) sobre el género como: "evento comunicativo creado por especialistas de una comunidad profesional o académica, para alcanzar unos objetivos comunicativos, de acuerdo con una serie de reglas convencionalmente aceptadas entre los miembros de una comunidad académica o profesional". Por lo tanto, cuando aludimos al concepto de género, nos referimos a "una forma convencionalizada de texto que posee una función específica en la cultura en laque se inscribe y refleja una finalidad del emisor previsible por parte del receptor" (Calvi et al., 2009, p. 71-72).

En este sentido, destacan Calvi et al. (2009), las lenguas de especialidad combinan un componente temático (que hace referencia a la comunicación especializada) y un componente social (vinculado al texto y a las finalidades pragmáticas del acto comunicativo). Ambos equivalen a la dimensión horizontal y vertical de las lenguas de especialidad, respectivamente. El primero incluye la finalidad epistemológica de cada campo del saber, aunque la relevancia de este componente no es la misma en todas las lenguas de especialidad. Por otro lado, la dimensión vertical está ligada al contexto y a la relación entre interlocutores, la función y los contenidos del acto comunicativo, esto es, al concepto de género discursivo:

\begin{abstract}
Entendemos el género discursivo (o género específico) como la unidad de comunicación que se ha desarrollado socio-históricamente en el ámbito de una actividad laboral específica. El género entendido así incluye tanto características léxico-gramaticales (fraseología, terminología, morfosintaxis, etc.) y discursivas (estructura, selección de datos, registro, etc.) como pragmáticas (funciones del discurso, roles de autor y lector, formas de cortesía, etc.) (Cassany, 2004, p. 42-3).
\end{abstract}

Asimismo, resaltan Calvi et al. (2009) en los ámbitos de especialidad, el concepto de género también se entiende como "un modelo institucionalizado para las interacciones sociales, porque puede constituir un marco para la comunicación y estar relacionado con la metodología, la epistemología, la ideología y la ontología social de una comunidad discursiva" (Calvi et al., 2009, p. 71). De hecho, los contextos situacionales enmarcados en los lenguajes de especialidad suelen caracterizarse por ser muy codificados 0 convencionalizados.

Por otro lado, Gómez de Enterría (2007, p. 169) recalca también la importancia innegable que tienen las Tecnologías de la Información y la Comunicación (TIC) hoy en día como fuente para extraer materiales de apoyo y documentos reales que ayuden a la adquisición de la lengua de especialidad. 


\subsection{Componente cultural}

Los lenguajes de especialidad se caracterizan también por la importancia que adquiere el componente cultural, más en el componente sociológico que en el temático. Sobre este hecho, Vittoria Calvi (2004) precisa que:

Conviene partir de un supuesto fundamental: la presencia de una dimensión horizontal (relacionada con los contenidos temáticos de una disciplina determinada, en cuanto productora de conocimiento), y una vertiente vertical (que depende del componente sociológico, es decir, el uso de la lengua como instrumento de comunicación entre los miembros de un grupo) (p. 108).

Gómez de Enterría (2007) confirma la importancia del componente cultural y de las relaciones socioculturales en la enseñanza de EFE:

Será necesario determinar cuáles son las necesidades comunicativas especializadas que tienen mayor demanda para la didáctica del español con fines específicos, delimitando los ámbitos de especialidad con fines didácticos [...] El docente deberá considerar todos y cada uno de los factores de carácter sociológico que condicionan la comunicación especializada. Cobra especial importancia la atención que requiere la competencia transcultural para el proceso de enseñanza/aprendizaje de una lengua funcional (p. 149-150).

\section{Propuesta didáctica}

Suponemos que el alumnado al que está dirigida nuestra propuesta didáctica tiene un conocimiento alto del español, situado en el nivel B2, por lo que, a escala global, se trata ya de un "usuario independiente" de la lengua. Por otro lado, entendemos que nuestro alumnado será plurilingüe y multicultural. Sus lenguas maternas serán el inglés, el francés, el ruso, el noruego, el italiano, el alemán, el neerlandés, el chino o el árabe. A grandes rasgos, pueden proceder de diversos estados de la Unión Europea o del África Occidental, como Marruecos, Mauritania o Senegal.

Nuestra propuesta didáctica tiene en cuenta las características a escala global correspondientes al nivel B2, especificado por el $\operatorname{MCER}(2002$, p. 26):

n. Es capaz de entender las ideas principales de textos complejos que traten temas tanto concretos como abstractos, incluso si son de carácter técnico, siempre que estén dentro de su campo de especialización. 
o. Puede relacionarse con hablantes nativos con un grado suficiente de fluidez y naturalidad, de modo que la comunicación se realice sin esfuerzo por parte de los interlocutores.

p. Puede producir textos claros y detallados sobre temas diversos, así como defender un punto de vista sobre temas generales, indicando los pros y los contras de las distintas opciones.

Desarrollaremos la competencia comunicativa-intercultural a un nivel pluridimensional, puesto que pretendemos abarcar aspectos lingüísticos y culturales directamente relacionados con el lenguaje de especialidad, caracterizado-como especificamos anteriormente-por el componente cultural. De acuerdo con el MCER (2002):

La competencia plurilingüe y pluricultural hace referencia a la capacidad de utilizar las lenguas para fines comunicativos y de participar en una relación intercultural en que una persona, en cuanto agente social, domina, con distinto grado, varias lenguas y posee experiencia de varias culturas. Esto no se contempla como la superposición o yuxtaposición de competencias diferenciadas, sino como la existencia de una competencia compleja e incluso compuesta que el usuario puede utilizar (p. 167).

Los contenidos de esta propuesta didáctica serán de tipo pragmático (formas de tratamiento), léxico-semántico (terminología del campo de la logística y la aduana) y sociocultural (tipología textual presente en el campo de la logística y la aduana e instituciones con las que se relaciona una empresa de este sector). Nuestro objetivo general es que el alumno conozca diversas características del lenguaje y de los procesos socioculturales de una empresa de logística y aduana, partiendo de contextos situacionales. Por medio de diversas situaciones reales en las que se trabajen las cuatro destrezas clásicas, el alumno adquirirá el conocimiento necesario para desenvolverse en varios contextos situacionales concernientes al lenguaje comercial de la logística y la aduana.

Un principio metodológico fundamental del Consejo de Europa ${ }^{4}$ ha sido que los métodos que se empleen en el aprendizaje, la enseñanza y la investigación de la lengua sean aquellos que se consideren más eficaces para alcanzar los objetivos acordados, en función de las necesidades de los alumnos como individuos en su contexto social. La eficacia depende de la motivación y de las características particulares de los alumnos, así como de la naturaleza de los recursos, tanto humanos como materiales, que puedan entrar en juego.

\footnotetext{
4 Información extraída del MCER (2002, pp. 141).
} 
Aunque el Consejo de Europa "ha fomentado un enfoque basado en las necesidades comunicativas de los alumnos y en el uso de los materiales y métodos que les permitan satisfacer esas necesidades y que resulten apropiados para sus características como alumnos" (MCER, 2002, p. 141), el MCER no concreta una metodología determinada, sino que presenta diversas opciones. Por ello, nos hemos decantado en esta propuesta didáctica por el enfoque comunicativo a lo largo del proceso de enseñanza-aprendizaje. La enseñanza comunicativa que propone dicho método tiene como objetivo principal: "que el alumno adquiera la capacidad de usar la lengua para comunicarse de forma efectiva" (Melero Abadía, 2004, p. 690).

En cuanto a los materiales y recursos didácticos, combinaremos presentaciones y explicaciones y desarrollaremos actividades de inmersión lingüística. Asimismo, proponemos hacer uso de diversos documentos elaborados por el propio docente o extraídos de Internet para realizar tareas basadas en contextos situacionales. También abogamos por utilizar documentos auténticos que muestren la realidad cotidiana con la que tiene que lidiar un empleado de una empresa de logística y aduana. Descartamos acudir a manuales para la enseñanza de Español como Lengua Extranjera (E/LE), puesto que los objetivos de esta propuesta didáctica se basan en desarrollar determinados aspectos del lenguaje de la logística y la aduana y consideramos que podemos cubrir dicha meta haciendo uso de documentos auténticos y de actividades elaboradas por el profesor.

En todo momento, se utilizará como lengua vehicular la lengua española, puesto que, como indica Melero Abadía (2004, p. 703) "el uso de la lengua en clase se convierte así en un objetivo del curso". Asimismo, debido a que contamos con alumnos plurilingües y multiculturales cuyas lenguas maternas difieren entre sí, parece aún más razonable hacer uso de una lengua común.

Por último, en lo que respecta a la evaluación de los resultados, se valorará activamente que el alumno haya adquirido los objetivos propuestos. Estimaremos la forma en la que este afrontará las simulaciones que realicemos, puesto que, al estar en un contexto de inmersión lingüística, es interesante evaluar cómo el alumno hará uso de los contenidos adquiridos, tanto los lingüísticos como los no lingüísticos y cómo responderá ante las posibles dificultades, es decir, a qué mecanismos de comunicación acudirá. Asimismo, creemos que debemos tener en cuenta en todo momento su fluidez oral y su corrección en la pronunciación, así como una forma de redactar acorde al nivel B2: uso de las formas verbales pertinentes, de las formas de tratamiento, de la puntuación correspondiente y de los marcadores lingüísticos. 
Para la elaboración de esta propuesta didáctica, sugerimos que el docente seleccione de antemano un corpus de documentos con los que pueda elaborar diversas tareas basadas en contextos situacionales. Creemos que el criterio para seleccionar el corpus debe ser que este se componga de documentos reales o de documentos elaborados por el profesor (o extraídos de Internet) pero que, en el caso de acudir a estos últimos, la fuente de información debe ser actual y fidedigna. Recomendamos que el corpus se componga al menos de los siguientes documentos:

q. Glosario de términos de logística y aduana: Este puede ser extraído de diversas páginas web (como de empresas de mensajería o de logística y aduana).

r. DUA (Documento Único Administrativo) Exportación: Documento real.

s. Un correo electrónico de un cliente que desea contratar los servicios de la empresa de logística y aduana: Este documento debe ser ficticio, por lo que puede ser elaborado por el propio profesor, teniendo en cuenta las necesidades de un posible cliente exportador/importador.

t. Una conversación telefónica entre un agente de aduanas y un funcionario de Hacienda del Estado: Este documento (que ha de ser plenamente ficticio) tendrá que ser elaborado también por el profesor. De este modo, recomendamos tomar como informante a un agente de aduanas para conocer cómo puede ser una conversación cotidiana telefónica entre estos interlocutores.

u. Muestrario del circuito verde, circuito naranja y circuito rojo: Documentos reales.

Respecto al cronograma de trabajo, hemos establecido que un curso específico de EFE para el campo de la logística y la aduana puede realizarse en tres sesiones, cada una de una hora y media de duración, aunque debemos tener en cuenta que el tiempo de impartición de un curso de este tipo puede variar al depender de varios factores: el organizador del curso (pues muchas veces son las propias empresas quienes desean que sus trabajadores adquieran formación específica); el perfil del alumnado (el conocimiento previo que tengan tanto de la lengua española como del mundo laboral en la cultura meta); el número de alumnos (que dependerá del organizador del curso) y el tiempo del que dispongamos, ya que muchas veces estos cursos se desarrollan fuera del horario laboral y el tiempo con el que contamos puede ser limitado. En todo caso, como docentes, debemos tener en cuenta en todo momento que un curso de EFE supone una formación lingüística y cultural esencial para el trabajador extranjero. Asimismo, presuponemos que el profesional contara con la experiencia y con el periodo de adaptación pertinente para garantizar su éxito laboral. 
Como señalamos al comienzo de este trabajo, establecemos la propuesta didáctica dentro del ámbito profesional de una empresa de logística y aduana de la ciudad de Las Palmas de Gran Canaria que recibe trabajadores extranjeros para facilitar el contacto exterior, debido a la relevancia económica que tiene el Puerto de la Luz y de Las Palmas.

Comenzaremos la primera sesión del curso comentando la transcendencia de este sector en Canarias para, de esta forma, encauzar el volumen de trabajo con el que pueda encontrarse el trabajador y que quizás difiera de aquel de su país de origen. A continuación, introduciremos las principales características del lenguaje de la logística y la aduana: registro formal para tratar a los clientes; registro informal para tratar a los profesionales del campo y uso de siglas y abreviaturas.

Una vez finalizada esta parte introductoria, comentaremos cuáles son las principales instituciones con las que debe lidiar una empresa de logística y aduana en el territorio español. Nos referimos a Hacienda del Estado o a la Consejería de Hacienda del gobierno regional que corresponda (en el caso de Canarias, Consejería de Economía, Hacienda y Seguridad del Gobierno de Canarias). Ambas instituciones disponen de página web. Dado que en la actualidad la amplia mayoría de los trámites aduaneros se realizan por vía telemática mediante el sistema $\mathrm{EDI}^{5}$, es recomendable que los profesionales extranjeros comiencen a familiarizarse con los servicios en línea de los que disponen las instituciones gubernamentales.

Para cerrar el comienzo de la primera sesión, aconsejamos proporcionar al alumno un glosario ${ }^{6}$ de términos básicos de la logística y a la aduana. El interés de este documento es que los alumnos relacionen la terminología específica de EFE con sus equivalentes en la lengua materna.

Iniciaremos la segunda sesión partiendo del primer contexto situacional concreto, ya que el alumnado se ha aproximado a la nueva realidad lingüísticocultural del EFE. Por ello, situamos al alumno en el supuesto contacto entre clientes y empresa. Hemos escogido el correo electrónico como canal de comunicación por ser el medio más habitual por el que los clientes contactan con las empresas, pues, en la actualidad, la gran mayoría de agencias de logística y aduana cuenta con dirección web. El cliente contacta con la empresa porque debe retirar una mercancía a su nombre y, por ello, debe realizar los

5 Siglas de Electronic Data Interchange (Sistema Electrónico de Intercambio de Datos).

6 En el apéndice de este trabajo aportamos un glosario de términos, abreviaturas y siglas básicas de la logística y la aduana. 
trámites aduaneros pertinentes. Solicita que la empresa de logística y aduanas le informe sobre la gestión y los costes. El objetivo es que el alumno conteste a dicho correo e informe al cliente de todo lo que necesita saber, además del proceso que seguirá la empresa. De este modo, sería conveniente recordar al alumno no solo las formas de tratamiento, sino también la importancia de conocer las formas de apertura y cierre de una carta y, huelga mencionar, guardar la corrección en la redacción. Por lo tanto, debe tener en cuenta las implicaciones gramaticales y estilísticas de la redacción.

Por otro lado, presentaremos un documento auténtico esencial en este campo laboral: el Documento Único Aduanero (DUA). Sirve de enlace entre las instituciones y la empresa de logística y aduana. Se almacena de forma telemática en la base de datos de la empresa, donde se incluyen los datos del cliente. Es conveniente proporcionarle a cada alumno un modelo de este documento auténtico, para que pueda familiarizarse con todos los datos que puede incluir, puesto que el formato del documento se asimila al formulario. Creemos que podemos centrarnos en explicar la finalidad y la utilización del documento, por lo que el profesor debe obtener información de antemano (puede consultar tanto páginas web como a profesionales nacionales del sector). Por otro lado, los alumnos obtendrán en sus empresas el conocimiento requerido para rellenar un formulario DUA de forma efectiva.

Para combinar los elementos de documentos auténticos y contextos situacionales, proponemos desarrollar el segundo contexto situacional, que consistirá en contactar con una institución gubernamental. Debemos resaltar la importancia de las relaciones telemáticas en las actuales empresas de logística y aduana y las instituciones gubernamentales. Acudiremos al documento que expone una conversación telefónica entre un agente de aduanas y un funcionario de Hacienda del Estado con el fin de aproximar a los alumnos a una posible conversación telefónica. Debemos advertir, nuevamente, sobre la importancia de mantener el registro formal y de dominar la terminología del tecnolecto de la logística y la aduana para que la conversación sea fluida y efectiva.

Como cierre del curso, procederemos a presentar a los alumnos los tres procedimientos mediante los que se realizan los trámites de aduana (conocidos como despachos en el tecnolecto de logística y aduana). Dichos documentos se denominan circuitos. La empresa de logística y aduana realiza los trámites necesarios que el Gobierno de Canarias (o el Gobierno regional) exige para que el cliente pueda apropiarse (conocido como levantar en el tecnolecto) de la mercancía. Dichos tres procesos se denominan: 
a. Circuito verde: A través de la realización del DUA, el levante de la mercancía es automático, es decir, el cliente debe abonar el impuesto correspondiente al Gobierno de Canarias y el coste de Aduanas a la empresa de logística y aduana. Además, se proporciona el número de autenticación (justificante de que la mercancía ha sido despachada).

b. Circuito naranja: La Aduana requiere una revisión del DUA. El cliente debe presentarse físicamente ante Aduanas o ante el Gobierno de Canarias. No supone ningún coste adicional.

c. Circuito rojo: Aduanas requiere inspeccionar físicamente la mercancía mediante tres procedimientos:

1. Vaciado completo del contenedor en el que se encuentra la mercancía.

2. Escaneado del contenedor para comprobar qué contiene.

3. Posicionado del contenedor, donde el inspector selecciona un bulto al azar y se lleva una muestra.

Dependiendo de lo que considere la autoridad pertinente, la mercancía del circuito rojo puede tener varios destinos: puede ser aprobada o puede ser confiscada y destruida, con la consecuente pena legal para el importador.

A continuación, le plantearemos al alumno el último contexto situacional en el que puede aplicar todo lo aprendido: El cliente (que ha contactado con la empresa previamente para informarse sobre los trámites aduaneros) ha aceptado la forma en la que se va a despachar la mercancía, y el empleado de la empresa de logística y aduana debe realizar los trámites necesarios con una determinada institución, bien Hacienda del Estado o el Gobierno de Canarias. El objetivo es que el alumno elabore un documento DUA de acuerdo con la información que proporciona el cliente.

Propondremos, al hilo del contexto situacional anterior, realizar un ejercicio de juego de rol. Partimos del supuesto de que se han realizado los trámites pertinentes relativos al DUA para que una determinada mercancía llegue a su destinatario. El juego de rol que se realice implica que un alumno tome el papel del agente de aduana y el otro, el del cliente. Como mediador entre el cliente y la Aduana, el profesional debe informar al primero sobre los últimos pasos que debe seguir. Deben imaginar que el cliente acude a la oficina de la empresa para recoger la documentación pertinente y se encuentran ante tres posibles opciones, pues su mercancía puede ser tramitada a través del circuito verde, el circuito naranja o el circuito rojo.

Cerraremos el curso solucionando todas las cuestiones que los alumnos planteen y les recomendamos mantener el contacto con el mundo de la 
logística y aduana en español, por lo que pueden hacer uso de diversos blogs o de redes sociales profesionales?.

\section{Conclusiones}

En primer lugar, el gran número de profesionales extranjeros que trabaja en empresas de logística y aduana en Canarias hace necesario ahondar en la enseñanza de EFE dentro de este campo. Creemos que es pertinente diseñar planteamientos didácticos basados en postulados teóricos que, además, garanticen una enseñanza de EFE de calidad. En este sentido, nuestra propuesta ha alcanzado los objetivos establecidos al comienzo del trabajo y responde de forma eficiente a una necesidad real existente en la sociedad.

Por otro lado, concluimos que el docente de cualquier campo de EFE debe obtener formación especial en el ámbito sociocultural del área de estudio. Es indispensable que acuda a profesionales del campo o a distintas fuentes de información que le proporcionen las aclaraciones pertinentes con respecto al campo profesional específico. El componente cultural que caracteriza a todo EFE hace que sea fundamental trabajar mediante contextos situaciones que acerquen al alumno a las costumbres sociales de la cultura meta y le permitan adaptarse a la realidad profesional.

La necesidad de hacer uso de documentos auténticos en cualquier campo de EFE es crucial, aunque los alumnos obtienen la formación adecuada en su lugar de trabajo. Asimismo, los documentos auténticos aportan al alumno información de primera mano sobre el material de trabajo. El profesor debe preparar a priori los componentes de trabajo que se utilizarán, elaborando por sí mismo aquellos que no sean auténticos o extrayéndolos de Internet, si existieran. En este caso, deben ser primordiales las fuentes de información vigentes y veraces.

Concluimos que esta propuesta didáctica puede llevarse a cabo no solo en empresas e instituciones privadas que precisen de asistencia lingüística y cultural para sus trabajadores, sino también en organismos públicos como el Servicio Público de Empleo español, con el fin de acercar a los inmigrantes al tecnolecto de la logística y la aduana y complementar así su formación; o en otras instituciones de carácter empresarial como la Cámara de Comercio de cada isla canaria, que ofrece de por sí formación en diversas lenguas.

Recomendamos el blog de las empresas Arola (http://www.arola.es/blog3/) y Tiba (http://www.tibagroup.com/es/logistica-transporte). 
Asimismo, creemos que este trabajo puede proyectarse hacia otros estudios futuros. Sería interesante indagar en el tecnolecto de la logística y aduana de España en relación con otras sociedades hispanohablantes y con sus sistemas comerciales. Asimismo, dado que Estados Unidos es un país en el que el índice de población hispanohablante aumenta cada año y las empresas que realizan transacciones comerciales con países hispanos son diversas, podría resultar provechoso elaborar un estudio en el que se relacione el tecnolecto de la logística y la aduana entre el inglés estadounidense y el español de países como México o Cuba, salvando las distancia entre las instituciones aduaneras de cada país.

\section{About the authors}

La Dra. María Nayra Rodríguez Rodríguez es profesora del Departamento de Filología Española, Clásica y Árabe de la Universidad de Las Palmas de Gran Canaria. Imparte clases en los Cursos de Doctorado y Posgrado, así como clases de Español como Lengua Extranjera. Ha dirigido más de veinte trabajos de investigación. Cuenta en su haber con varias publicaciones de la especialidad de lengua española y de didáctica del español. Ha impartido clases en varias universidades nacionales e internacionales como la Universidad de Alcalá de Henares, la Universidad de la República Dominicana (UNAPEC) o la Universidad de Turku (Finlandia). Ha sido coordinadora de las ediciones del título propio del Máster de Español como Lengua Extranjera de la Universidad de Las Palmas de Gran Canaria. Ha dirigido cursos de extensión Universitaria y ha participado con comunicaciones en Congresos Nacionales e Internacionales. Ha estado en las Universidades de Bilkent (Turquía) y Ljubliana (Eslovenia).

Sara González Gil es alumna doctoranda de la Universidad de Las Palmas de Gran Canaria en el Programa de Doctorado de Español y su Cultura, donde realiza su tesis doctoral, dirigida por la Dra. María Nayra Rodríguez Rodríguez. Ha realizado una estancia de investigación en el Departamento de Español en la Universidad de Turku (Finlandia), bajo la supervisión de la Dra. Angela Bartens. En esta misma institución, ha impartido un curso de Metodología de la enseñanza del español como lengua extranjera a alumnos finlandeses. Asimismo, ha participado en el Congreso InnoEducaTIC en la Universidad de Las Palmas de Gran Canaria. Su línea de investigación se centra en la Lingüística Aplicada, en concreto la didáctica 
del español como lengua extranjera y la lingüística contrastiva españolfinés.

\section{Article history}

Paper received: $08^{\text {th }}$ June 2015

Paper received in revised form and accepted for publication: $28^{\text {th }}$ March 2016

\section{Referencias}

Aguirre Beltrán, B. (2004a). Análisis de necesidades y diseño curricular. En VV.AA., Vademécum para la formación de profesores. Enseñar español como segunda lengua (L2)/lengua extranjera (LE) (pp. 643-664). Madrid: Sociedad General Española de Librería.

Aguirre Beltrán, B. (2004b). La enseñanza del español con fines específicos. En VV.AA., Vademécum para la formación de profesores. Enseñar español como segunda lengua (L2)/lengua extranjera (LE) (pp. 1109-1127). Madrid: Sociedad General Española de Librería.

Bathia, V. K. (1993). Analysing Genre: Language in Proffesional Settings. Londres: Longman.

Cabré, M. T. (1993). La terminología. Teoría, metodología, aplicaciones. Barcelona: Antártida/Empúries.

Calvi, M. V. (2004). El componente cultural en la enseñanza de español para fines específicos. En V. de Antonio et al. (Eds.), Español para Fines Específicos. Actas del II CIEFE. Segundo Congreso Internacional de Español para Fines Específicos (CIEFE), (pp. 107-122). Ámsterdam, Noviembre 2003.

Calvi, M. V. et al. (2009). Las lenguas de especialidad en español. Roma: Carocci editore e Studi Superiori.

Cassany, D. (2004). La lectura y la escritura de géneros profesionales en EpFE. En V. de Antonio et al. (Eds.), Español para Fines Específicos. Actas del II CIEFE. Segundo Congreso Internacional de Español para Fines Específicos (CIEFE), (pp. 40-64). Ámsterdam, Noviembre 2003.

Centro Virtual Cervantes (1997-2012). Diccionario virtual de términos clave de E/LE.

Dudley-Evans, T. y St. John, M. J. (1998). Developments in English for Specific Purposes. Cambridge: Cambridge University Press.

Fajardo Domínguez, M. (2000). ¡Dios mío! ¿Yo español de los negocios? ¡Pero si soy de letras!. En M. Bordoy, A. van Hooft y A. Sequeros (Eds.), Español para Fines Específicos. Actas del I CIEFE. Primer Congreso Internacional de Español para Fines Específicos (CIEFE) (pp. 194-200). Ámsterdam, Noviembre 2000. 
Gómez de Enterría, J. (2007). La enseñanza del español con fines específicos. En M. Lacorte (Ed.), Lingüística aplicada del español (pp. 149-181). Madrid: Arco Libros.

Hernández, M. J. y Zanón, J. (1990). La enseñanza de la comunicación en la clase de español. Cable, Revista de didáctica del español como lengua extranjera, 5, 12-19.

Melero Abadía, P. (2004). De los programas nocional-funcionales a la enseñanza comunicativa. En VV.AA., Vademécum para la formación de profesores. Enseñar español como segunda lengua (L2)/lengua extranjera (LE) (pp. 689-714). Madrid: Sociedad General Española de Librería.

Moreno Fernández, F. (1999). Lenguas de especialidad y variación lingüística. En: S. Barrueco, E. Hernández y L. Sierra (Eds.), Lenguas para fines específicos (VI). Investigación y enseñanza (pp. 1-14). Alcalá de Henares, Universidad de Alcalá, 1999.

Ministerio de Educación, Cultura y Deporte (2002). Marco común europeo de referencia para las lenguas: aprendizaje, enseñanza, evaluación, Madrid, Secretaría General Técnica del MECD y Grupo Anaya S.A, traducido y adaptado por el Instituto Cervantes.

Neila González, G. (2010). Aplicación del método de los casos en la enseñanza de EFE: el caso del español de los negocios. Memoria de máster, Universidad de Jaén-FUNIBER. MarcoELE, 11.

Rodríguez Díez, B. (1981). Las lenguas especiales. El léxico del ciclismo. León: Colegio Universitario de León.

Swales, J. M. (1990). Genre Analysis. Cambridge: Cambridge University Press. 


\section{Apéndice}

\section{Glosario de términos, abreviaturas y siglas básicas de la logística y la aduana $^{8}$}

\section{Ad Valorem}

Es un término latino bastante común que significa "de acuerdo al valor". Todos los gravámenes e impuestos pueden calcularse sobre la base del valor.

\section{Carnet ATA}

El Carnet ATA es un documento internacional de aduanas. Emitido bajo los términos de la Convención de la ATA y la Convención de Estambul, incorpora una garantía internacional válida.

El carnet puede ser utilizado en lugar de los documentos de aduanas nacionales y como certificado de seguridad para los impuestos y aranceles de importación. Esto incluye la admisión del tránsito temporal de bienes.

El Carnet ATA también se puede solicitar para controlar la exportación temporal y la reimportación de bienes. Sin embargo, en este caso la garantía internacional no se aplica.

\section{Certificado de Origen}

Documento específico que certifica que las mercancías a las que se refiere el certificado se originan en un determinado país.

Este Certificado también puede incluir una declaración del fabricante, productor, proveedor, exportador u otra persona competente.

\section{Certificado Fitosanitario}

Certificado emitido por una agencia del Gobierno (normalmente el Departamento de Agricultura) para cumplir con los reglamentos de importación de los países extranjeros.

8 Extraído de http://www.dhl.es/es/express/aduanas/glosario_de_aduanas.html y https://www. apr.es/glosario. 
El certificado indica que un envío ha sido inspeccionado y está libre de pestes dañinas y enfermedades fitosanitarias.

\section{CIF}

Es una abreviatura comúnmente utilizada en algunos contratos internacionales, cuando el precio de venta incluye todos los "Costes, Seguro y Flete" correspondientes a las mercancías vendidas.

Esto significa que el vendedor organiza y paga todos los gastos relativos al envío de la mercancía, desde el lugar de exportación hasta el de importación.

En estadística comercial, "el valor CIF" significa que todas las cifras de importación o exportación se calculan sobre esta base, independientemente de la naturaleza de las transacciones individuales.

\section{Coste de Descarga}

Coste de los bienes importados en el punto de entrada en un país, incluyendo el flete, seguro, puerto y derechos de muelle.

Todos los cargos que apliquen una vez que los bienes hayan dejado el punto de importación, no están incluidos.

\section{CPA}

Código de Procedimiento Aduanero.

\section{Declaración Aduanera}

Cualquier declaración o acción que ofrezca información o detalles solicitados por Aduanas en la forma aceptada por esta.

Se considera más eficiente exonerar pequeñas cantidades de aranceles y impuestos que cobrarlos.

\section{Declaración de Carga / Manifiesto de Carga}

El Manifiesto de Carga enumera las mercancías que se van a transportar en un determinado medio de transporte. 
La Declaración facilita detalles comerciales de los artículos, tales como:

- Número de documento de transporte

- Remitente y consignatario

- Marcas y número

- Cantidad y tipo de paquete

- Descripción y cantidad de artículos

\section{DUA}

Documento Único Aduanero. No necesario en el comercio intracomunitario. Sí para terceros países (importación y exportación).

\section{EDI}

Electronic Data Interchange - intercambio electrónico de datos.

\section{Factura Consular}

Declaración con el detalle de la mercancía que se envía, emitido por el consulado del país. Esta factura se solicita por algunos gobiernos extranjeros que desean tener mayor control sobre sus importaciones.

\section{Factura Proforma}

Factura presentada por un proveedor con anterioridad al envío de la mercancía, en la que informa al comprador sobre el tipo y cantidad de artículos que envía, valor y especificaciones (peso, tamaño, etc.).

\section{IGIC}

Impuesto General Indirecto Canario. El IGIC es un impuesto general aplicado en las Islas Canarias respecto a las ventas o prestaciones de servicios que constituye el tributo básico de la imposición indirecta canaria.

\section{Impuesto Preferencial}


Es un impuesto menor que depende del país de origen y está basado en el valor de las mercancías.

\section{INCOTERMS}

Es la abreviatura de la Cámara Internacional de Comercio relativa a los Términos de Venta. Su objetivo es establecer criterios definidos sobre la distribución de gastos y transmisión de riesgos, entre exportador e importador.

\section{Intermediación}

Se refiere habitualmente a los agentes de aduanas que realizan el despacho de envíos entrantes o salientes.

\section{IVA}

Impuesto al Valor Agregado.

\section{Mercancía en Depósito}

Es mercancía almacenada en un depósito seguro. Mientras permanezca allí no está sujeta a cargos o impuestos de importación. Esto es así hasta que se pague el impuesto o los bienes sean exportados o legalmente tramitados.

\section{MTD}

Multimodal Transport Document. Son los documentos de transporte multimodal, normalmente emitidos por las líneas navieras de contenedores para cubrir el despacho de mercancías de un lugar de toma de cargo a un lugar de entrega.

\section{SDT}

Declaración de cargadores para el transporte de mercancías peligrosas.

\section{Sistema Armonizado}


Es el sistema internacional publicado por la Organización Mundial de Aduanas que establece de forma sistematizada las mercancías que se envían a través del comercio internacional.

Estas se agrupan por Secciones, Capítulos y sub-Capítulos, cada uno con sus propias reglas.

\section{Valor en aduana}

Para calcular los derechos Aduaneros que hay que aplicar, la Aduana define el concepto de Valor en Aduana, que es el de la mercancía más todos los gastos (seguro, transporte, etc.) que se hayan producido hasta el momento de pasar la aduana. Sobre este valor en aduana, se aplicará el tipo de arancel a que esté sometida la mercancía. El arancel a aplicar depende de la mercancía y el país de origen. Al resultado de aplicar el arancel al valor en aduana, se aplica el IVA correspondiente. Este valor es el Valor de la Mercancía.

\section{Zona Franca}

Es un área dentro de un país (puerto, aeropuerto, depósito o cualquier área específica) considerada como fuera del territorio aduanero.

Los importadores pueden traer mercancías de origen extranjero a estas áreas sin pagar aranceles o impuestos. Esto es posible cuando el correspondiente proceso esté en trámites, un envío transfronterizo o re-exportación.

Hace años cuando las tarifas eran superiores, las zonas francas solían ser numerosas y prósperas. Algunas aún existen en capitales, empalmes de líneas de transporte o grandes puertos, Pero su número y prominencia han declinado a medida que las tarifas han ido bajando en los últimos años.

Las zonas francas también se conocen como "puertos libres", "depósitos libres", "zonas de libre comercio" o "zonas de comercio internacional." 